\title{
The relationship of forest and improved grassland to soil water storage and its implication on Natural Flood Management in the Scottish Borders
}

\author{
N.A.L. Archer ${ }^{*}$, M. Bonell ${ }^{1}$, N. Coles ${ }^{2}$, A.M. MacDonald ${ }^{3}$, \\ R. Stevenson ${ }^{2}$ and P. Hallett ${ }^{4}$ \\ UNESCO Centre, University of Dundee, Perth Road, Dundee DD1 4HN, Scotland \\ ${ }^{2}$ Centre for Ecohydrology, University of Western Australia, 32 Stirling Highway, Crawley WA 6009 \\ ${ }^{3}$ British Geological Survey, Murchison House, West Mains Road, Edinburgh EH9 3LA, Scotland \\ ${ }^{4}$ James Hutton Institute, Invergowrie, Dundee DD2 5DA, Scotland \\ *Email:n.a.l.archer@dundee.ac.uk
}

\begin{abstract}
An investigation was undertaken in the Eddleston Catchment, Scottish Borders, to evaluate the impact of land cover on soil permeability (measured as field saturated hydraulic conductivity, $K f s$ ) and its implication on dominant stormflow pathways on hillslopes. $K f_{s}$ was measured at a depth range of 4 to $15 \mathrm{~cm}$ and 15 to $25 \mathrm{~cm}$ using the Talsma Constant Head Well Permeameter across three paired sites of adjacent tree and grassland cover. The tree types were 500-year old mixed woodland, 180-year old mixed woodland, and 45-year old Scots pine plantation. Paired grids of different land cover were compared on similar soil texture and topography. Dominant stormflow pathways were inferred by overlaying rainfall-intensity-duration-frequency (IDF) data for different return periods on to $K f_{s}$ boxplots. The resulting data from different land covers provide information for understanding sources and sinks for stormflow pathways under different land covers and topography in the context of reducing flood peak flows. It was found that the 500- and 180-year old mixed forests have an excellent capacity for rainfall infiltration where $K f_{s}$ values were almost five to six times more than those for grassland areas and is a sink for 1-in-100 year rainfall IDF events. The study also discusses the importance of understanding the effect of forest cover of different ages, where the hydrological soil properties change through time.
\end{abstract}

\section{Introduction}

The Flood Risk Management (FRM) (Scotland) 2009 (2009) Act promotes a sustainable approach to flood risk management. Section 20 of the Act requires SEPA to assess whether the:

'Alteration ... or restoration of natural features and characteristics ... could contribute to the management of flood risk for the district'.

There have been extensive literature reviews, as well as specific catchment studies, on the effects of upland forest cover on flood flow in humid temperate, western Europe (Robinson et al., 2003), the UK (O'Connell et al., 2004; Nisbet et al., 2011) and in the context of NFM for Scotland (Price et al., 2010). All these reviews suggest that forest cover, or land use management of forest environments, influence flood flows at the local-scale, but that the aggregation of these effects are more difficult to detect or cause little impact at the regional or large scale. With increasing scale, the causal factors are centred on the complex interactions between rainfall (temporal and spatial variability), topography, soil and land cover types (Bloschel et al., 2007).

Using input-output relationships of stable isotopes from 14 Scottish catchments, Soulsby et al. (2011) estimated that mean transit times of rainfall to streamflow ranged from 60 days to $>10$ years and were mainly controlled by catchment soil cover and drainage density; hardly surprising in Scotland where $66 \%$ of land consists of low vegetation cover such as grassland, mires and heather moorland (Mackney et al., 1998) and natural woodland cover in Scotland declined by 50 per cent at the beginning of farming in $4000 \mathrm{BC}$ to about 4 per cent by the 18th century (Armit and Ralston, 2003). Under such vegetation cover and long term deforestation the possibility for the vegetation to intercept, transpire and store rainfall is reduced. Numerous studies have found that forests have higher infiltration rates than grassland (Carroll et al., 2004; Scheffler et al., 2011), but few studies have investigated infiltration rates of different aged forests.

At the local scale, infiltrability and soil hydraulic conductivity (Ks) are key soil properties as they activate surface and near-surface flow paths that influence runoff generation (Bonell et al., 2010; Elsenbeer, 2001), which could provoke dominant storm flows and impact upon soil erosion (Bonell and Bruijnzeel, 2005). When considering planting woodlands for NFM it is important to have an understanding of baseline infiltration rates, i.e. maximum rates of infiltration of woodland in relation to rainfall duration and intensity, to understand runoff generation. Therefore, in order to improve our understanding of the possible increased soil hydraulic conductivity and soil water storage that forests develop over time, we aim to investigate field hydraulic conductivity $(K f s)$ 


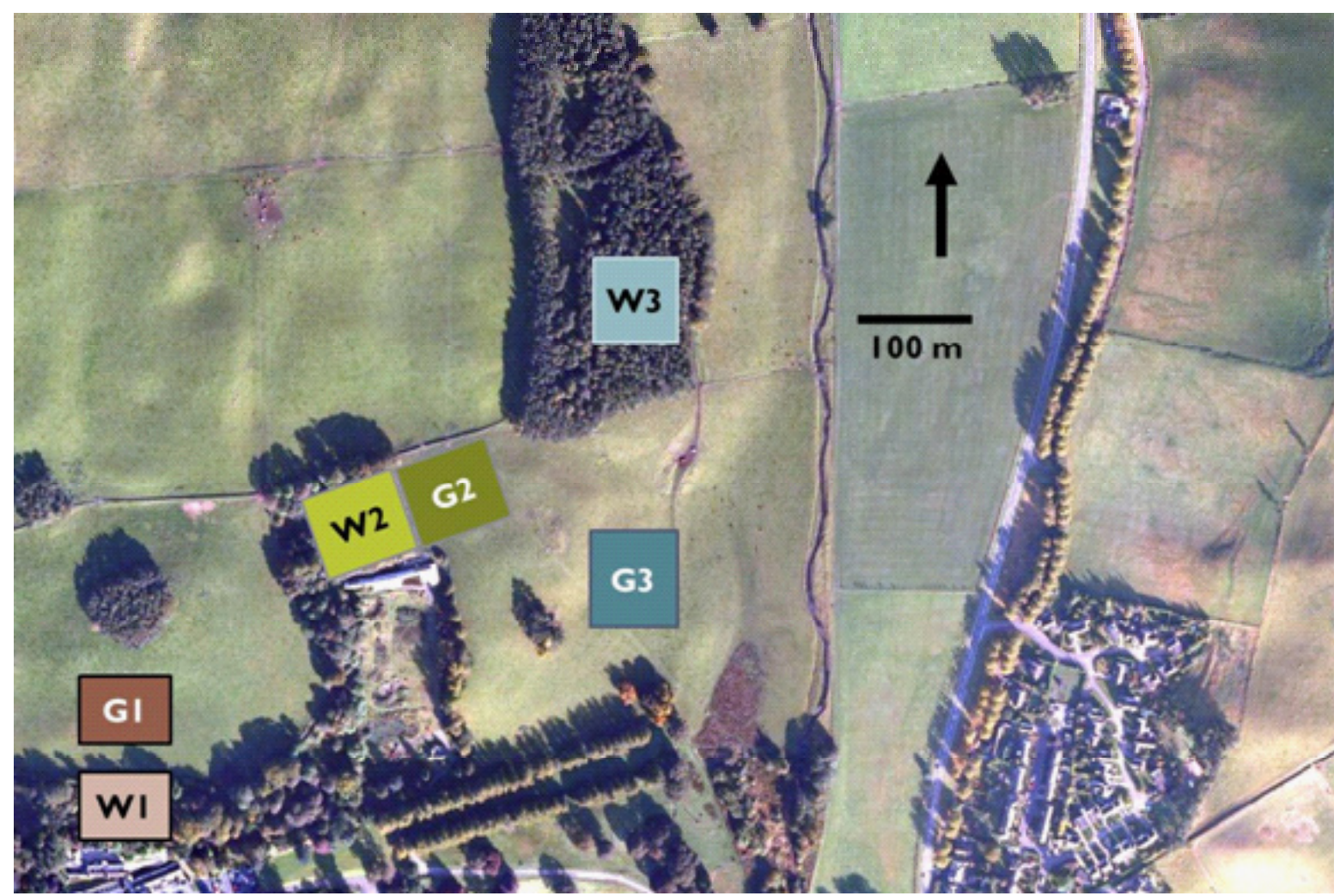

Figure 1 Aerial Photo of the Field Study Site. Site 1:G1 and W1 situated at the top of the slope, site 2:G2 and W2 located on a relatively flat part of the slope and site: $G 3$ and W3 is on the steepest most gravelly part of the slope. W denotes woodland and $G$ is grassland.

in 500- and 160-year deciduous mixed forests and a 45 -year old conifer plantation, and compare these land covers to adjacent grazed grassland.

This collaborative investigation has been undertaken alongside groundwater characterisation within the same experimental hillslope and floodplain with the ultimate aim to link surface and sub-soil permeability to groundwater dynamics. The characterisation and conceptual modelling of the hillslope-floodplain hydrological system for an upland hillslope-floodplain environment in Eddleston, Scotland, is described in a companion paper by Ó Dochartaigh et al. (2012).

\section{The study area}

The Eddleston Water experimental catchment has been set up to assess the effectiveness and efficiency of NFM and provide an integrated catchment management approach towards restoring the Eddleston riparian zone in the context of sustainable flood risk management. It covers an area of $69 \mathrm{~km}^{2}$, with the Eddleston Water flowing north to south feeding into the River Tweed at Peebles. Land cover in the catchment is predominantly improved grassland, with a coniferous plantation covering the higher ground in the west and semi-improved grassland and heath covering the higher ground in the east.

To limit differences in soil characteristics and topography that may affect soil permeability, the study site situated at Darnhall Mains was divided into three sites containing pairs of grazed grassland cover and tree cover (Figure 1). Site 1 on the higher slope contains grazed grassland (G1) and a 500-year old deciduous woodland (W1); lower down the slope on a flat area site 2 contains a grazed grassland (G2) and a mixed 180-year old mixed woodland (W2) and on the steepest ( $\sim 12 \%$ slope) part of the hillslope is grazed grassland (G3) and a shelter belt of 45-year old Scots pine (W3). G3 and W3 are not adjacent because there is a gully between them and these two sites seemed to be the most representative to compare results. A summary of site characteristics are given in Table 1. Particle size analysis of soil samples taken from each of the study sites shows that the silt fraction increases down slope to the riparian zone. Gravels are more abundant on the steeper slope, occurring at the top of the slope, but becoming rare in the floodplain.

\section{Methodology}

Rainfall intensity-frequency-duration analsyis (IDF)

IDF characteristics were calculated for the study site using a depth-duration-frequency model (Faulkner, 1999). When rainfall intensity $\left(\mathrm{mm} \mathrm{hr}^{-1}\right)$ exceeds the measured $K f s$ value, the threshold of infiltration overland flow (IOF) has been

Table $1 \quad$ Site description, grid sampling size, and Kfs measurement depths

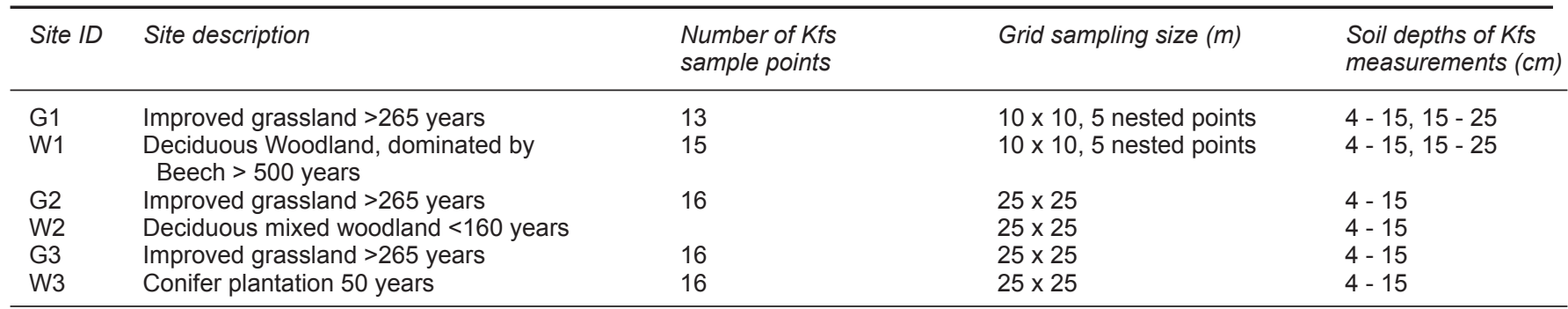


breached. By comparing the $K f S$ value with rainfall intensity, the occurrence and location of IOF can be inferred (Bonell, 2010).

\section{Comparative analysis of $\mathrm{K} f$ s formula}

To be able to compare $K f s$ IDF characteristics, a comparative analysis of different formulas to estimate $K f s$ was carried out. For each formula investigated, the same field data were used, these included: steady-state flow out of an auger hole $(Q)$, auger hole radius $(a)$ and auger hole head height $(H)$. Kfs was calculated under five methods:

(1) The Glover solution is based on the Laplace equation (Zangar, 1953) and defined by:

$$
K f s=\frac{Q\left[\sinh ^{-1}\left(\frac{H}{a}-1\right)\right]}{2 H^{2}}
$$

where $Q$ is steady state flow out of the auger hole, $H$ is auger hole head height and $a$ is auger hole head height.

(2) Glover $\mathrm{C}$ factor correction and Numerical correction: The resulting values from the Glover solution were corrected in two ways: (1) using a $C$ factor correction (Equation 30, p. 256 in Reynolds et al. (1983) ) to solve for the effect of gravity, particularly important when $H / a$ is $<5$ (Elrick and Reynolds, 1992), and (2) a theoretical correction (numerical $C$ factor) which uses quadratic functions to approximate the boundary conditions along the submerged wetted surface of the well, explained by Reynolds et al. (1983) p.258.

(3) Glover smearing $\times 2$ and Numerical correction $\times 2$ : The Kfs results from method 2 were multiplied by 2 , which takes into account smearing of the auger hole. Talsma (1987) suggested multiplying the resulting $K f_{s}$ by 2 based on analysis of 12 Australian soils.

(4) Effect of capillarity for three different soil types: As the Glover solution attributes all flow out of the cavity as saturated flow, unsaturated flow (or capillary flow) is neglected. Elrick et al. (1989) added the component of capillarity of unsaturated flow based on the Richard's equation (Equation 1, in Elrick and Reynolds, 1992) by taking a soil description for each well to classify the soil into four textural groups which relate to four pre-defined $\alpha^{*}$ values: $0.01 \mathrm{~cm}^{-1}, 0.04 \mathrm{~cm}^{-1}, 0.12 \mathrm{~cm}^{-1}$. Each soil type has a different $C$, which is dependent on the H/a ratio (Reynolds and Elrick, 1987).

(5) Removing the component of capillarity from the Richard's equation used in method 4 for the three soil types. To assume zero capillarity, $\alpha^{*}$ was set to infinity by setting the term $2 \pi H / C$ to zero for the three soil types and $K f s$ was again calculated.

\section{Measurement of Hydraulic conductivity (Kfs)}

Within each study site, a grid system was measured to locate each sample point. The grid sampling size and soil depth for $K f s$ measurements are shown in Table 1. Kfs was measured using a constant head well permeameter (CHWP) as designed by Talsma and Halam (1980). A stony layer below $15 \mathrm{~cm}$ at sites $\mathrm{G} 2$ and $\mathrm{W} 2$ restricted augering below $15 \mathrm{~cm}$. To ensure a comparative data set across the study sites, the auger hole depth was therefore set to $15 \mathrm{~cm}$. To avoid interaction of the soil surface, the constant falling head level was set to $4 \mathrm{~cm}$ below the soil surface, thus providing a head $(h)$ of $11 \mathrm{~cm}$ for all measurements at soil depths of $15 \mathrm{~cm}$. At site $\mathrm{G} 1$ and $\mathrm{W} 1$ it was possible to auger to $25 \mathrm{~cm}$. Therefore, for these sites a second CHWP measurement was taken from $15 \mathrm{~cm}$ to $25 \mathrm{~cm}$. A $6 \mathrm{~cm}$ diameter auger was used throughout the investigation. The auger hole radius (a) was generally between $3.25-3.5 \mathrm{~cm}$. This gave an $H / a$ value of approximately 3 . A pre-wetting phase of 20 minutes was carried out before starting the permeameter test to reduce the time to steady state flow and ensure that each measured point was saturated (Talsma and Hallam, 1980).

\section{Results}

\section{Comparison of $K f$ s formulas}

Figure 2 shows the large range of estimated $K f S$ depending on the use of different solutions. A 1:1 line for the Glover solution in Figure 2 was plotted to compare all the estimated $K f s$ values against the Glover solution (Equation 1).

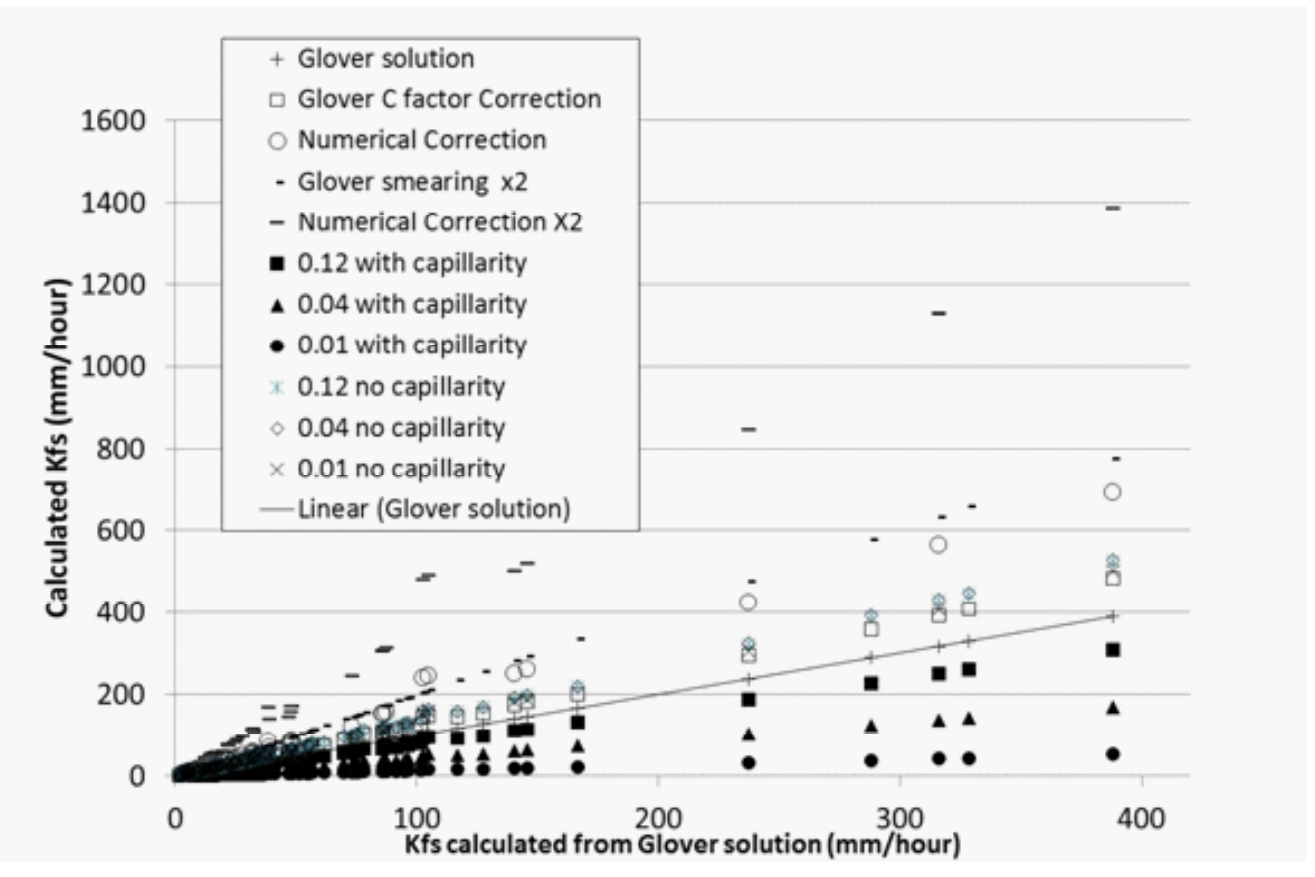

Figure 2 Comparison of Kfs values against the Glover solution (Equation 1), shown as 1:1 line. 
Following this comparison of different formulas, field conditions were also considered to choose the best solution to estimate $K f s$. Four important factors were considered:

- The glacial alluvial soils were particularly heterogeneous and at times could potentially be classified into more than one soil textural group to estimate $\alpha^{*}$. It was decided that the four textural categories to estimate $\alpha^{*}$ were not suitable for the field area and the resulting $K f s$ values which took into account unsaturated flow were too low for the in-situ field conditions. Poor estimates of $\alpha^{*}$ can introduce errors as large as $210 \%$ (Bosch, 1997).

- Because of the persistent rainfalls occurring over the study site, soil moisture content is maintained at over $30 \%$. Additionally auger holes were pre-wetted for at least 20 minutes to attain steady state. This combination would minimise the effects of soil capillarity and therefore it is plausible to assume zero capillarity.

- The difficulty of augering below $15 \mathrm{~cm}$ in most areas caused the $H / a$ ratio to be particularly low $(\sim 3)$ and therefore it was important to correct the Glover solution for the effect of gravity (as done in method 2).

- The effects of smearing which Talsma (1987) suggested decrease the $K f s$ values by $50 \%$ on 12 Australian soils, is considered to be less pronounced for the soils of the studied sites, because the soil texture of the field soils contained less than $8 \%$ clay content and gravel content was high. Therefore, the $K f s$ values multiplied by 2 to take smearing into account were considered to over-estimate $K f s$.

Following the results in Figure 2 and considering the field conditions, method 2 (the Glover solution corrected for the effect of gravity) was preferred as providing the most representative $K f s$ values to allow for comparison of measured $K f s$ to rainfall intensity-duration-frequency curves. Therefore all subsequent $K f s$ results are calculated using method 2.

\section{Statistical analysis of measured Kfs data}

Spatial dependence of the $K f s$ data was checked by plotting semi-variograms for each site using the ESRI Geostatistical Analyst in ArcGIS10. Nested points with distances between 1 to $5 \mathrm{~m}$ were also measured at site 1 to investigate autocorrelation of $K f s$. $K f_{s}$ measured at points 25 and $10 \mathrm{~m}$ apart were found to have no spatial correlation. Very weak spatial correlation was found up to four metres. Points less than $4 \mathrm{~m}$ apart were therefore taken out for analysis of variance. Spatial maps of the measured $K f s$ data were also interpolated using Inverse Distance Weighting to investigate the spatial relationship of the data with land cover. Figure 3 shows the striking spatial change of $K f s$ between a grazed grassland area (G1) and a fenced woodland area (W1). There is only $30 \mathrm{~m}$ distance between the first lines of $K f_{s}$ measurements within the woodland and grassland areas.

\section{Rainfall intensity-frequency-duration analysis and $\mathbf{K} \boldsymbol{s}$} estimated from the Glover solution corrected for the effect of gravity and inferred dominant stormflow pathways

Kfs values were normalised using log to the base 10 transformation. Analysis of variance using Minitab Version16 indicated that $K f s$ under woodland for sites 1 and 2 were very significantly higher $(p<0.001)$ than $K f s$ under grassland for sites 1 and 2 and the coniferous forest (site 3 ), as shown in Figure 4A. Coniferous forest (W3) had a slightly higher range of $K f s$ in comparison to grassland for sites 1 and 3, but was significantly higher than G2 $(p<0.02)$. Mean $K f_{s}$ for woodland areas was five and six times higher than adjacent grassland areas for sites 1 and 2 respectively. At site $1, K f s$ at 4 to 15 and 15 to $25 \mathrm{~cm}$ soil depth were highly significantly different $(p<0.001)$ between adjacent grassland and woodland. For both woodland and grassland areas at site 1, the $K f_{s}$ of the surface soil layer was approximately four times higher than the deeper soil depth. The range of $K f S$ at the deeper soil layer under woodland is similar to the range of the $K f S$ of the upper soil layer in the grassland (Figure 3B).

Figure 4A and 4B illustrates clearly that the 500year old deciduous and 180-year old mixed woodland have a greater capacity to infiltrate more than 1 - in-100 year storm events. On the other hand the upper quartiles in all grazed grassland areas are below the 1-in-100 year storm event, which infers that infiltration-excess overland flow will occur for high storm events. Surface overland flow is most likely to occur in the most impermeable grassland area (G2) for a 1-in10 year storm event. In summary, the rank of median $K f s$ for the 4 to $15 \mathrm{~cm}$ soil layer is $\mathrm{W} 1>\mathrm{W} 2>\mathrm{W} 3>\mathrm{G} 1>\mathrm{G} 3>\mathrm{G} 2$.

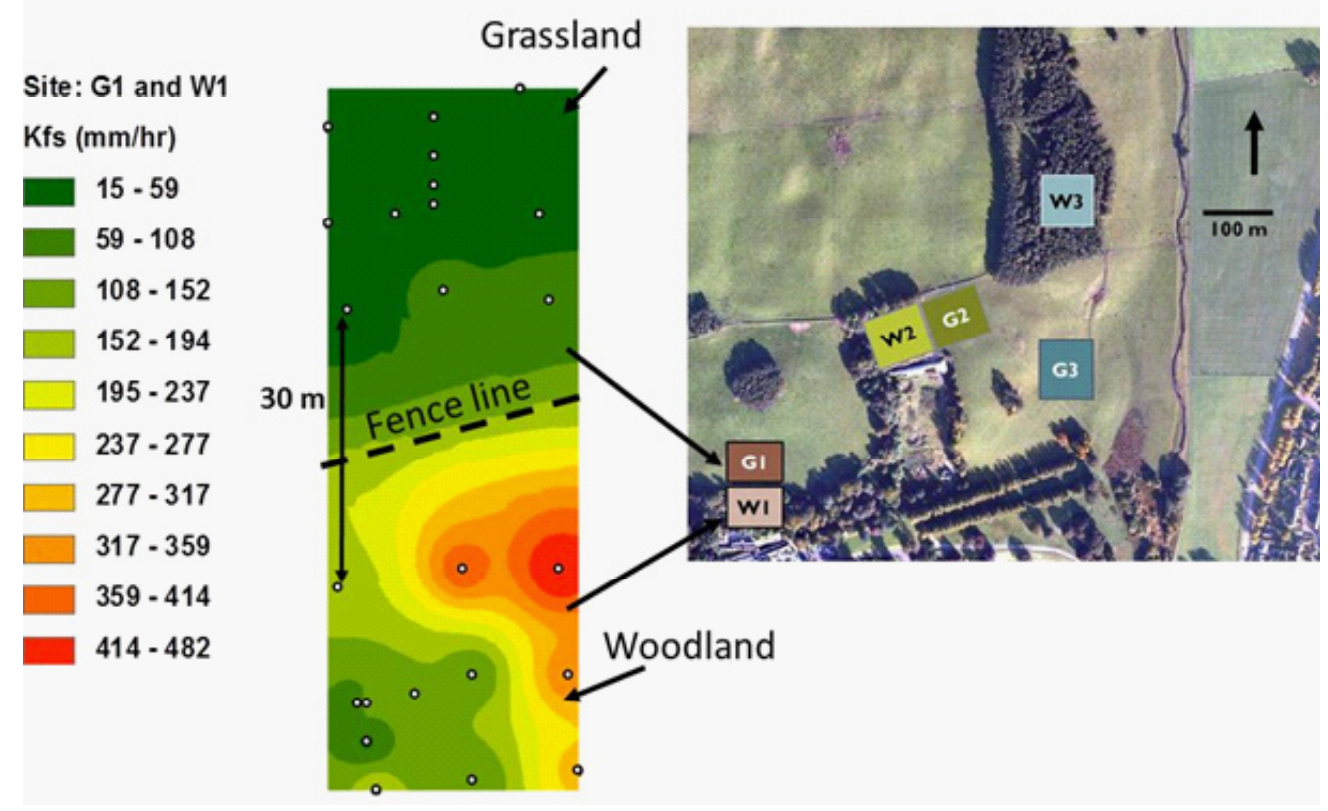

Figure 3 A spatial interpolation using Inverse Distance Weighting of Kfs measurements (white dots on the map) of site 1 woodland (W1) and grassland (G1). The two areas were separated by a fence line and the location of the interpolated map is shown on the aerial photo. 

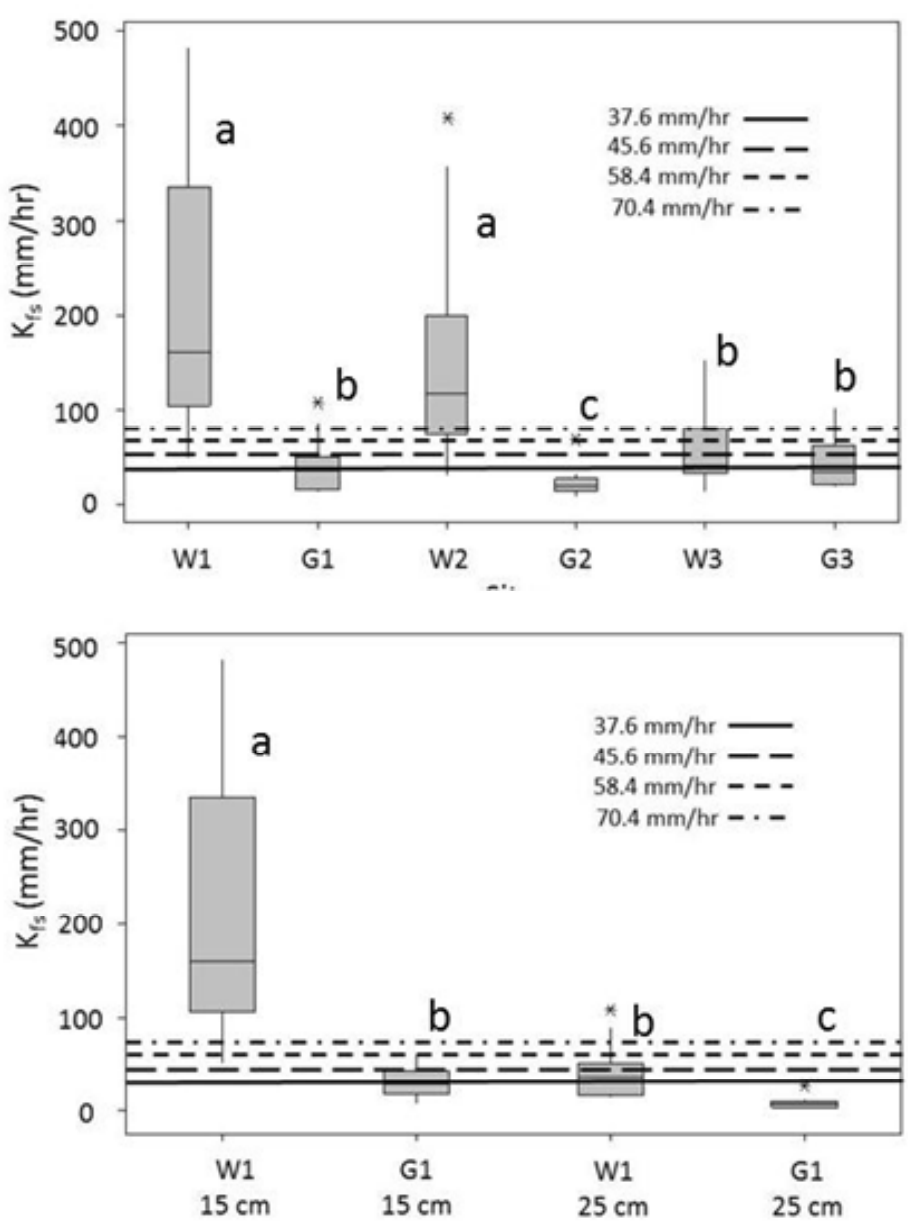

Figure 4 (Top) Box plots of measured Kfs for each field site measured between 4 to $15 \mathrm{~cm}$ soil depth. (Bottom) Box plots of measured $K f$ s for site $1 \mathrm{Gl}$ and $W 1$ for two soil depths 4 to $15 \mathrm{~cm}$ and 15 to $25 \mathrm{~cm}$. The superimposed black and dashed lines are

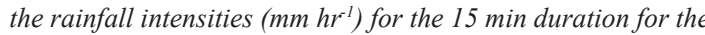
selected return periods of 1 in 10 years $\left(37.6 \mathrm{~mm} \mathrm{hr}^{-1}\right), 1$ in 20 years (45.6 $\left.\mathrm{mm} \mathrm{hr}^{-1}\right), 1$ in 50 years $\left(56.4 \mathrm{~mm} \mathrm{hr}^{-1}\right)$ and 1 in 100 years $\left(70.4 \mathrm{~mm} \mathrm{hr}^{-1}\right)$. The small letters denote highly significant differences $(p<0.01)$ between sites.

At site 1 under grassland (G1), the 1- in-10 year storm event is almost equivalent to the $K f_{S}$ median for the 4 to $15 \mathrm{~cm}$ soil layer, but the $K f s$ range of values for the deeper soil layer is well below the smallest storm event (Figure 4B). This infers that under heavy rainfall, the rainfall which infiltrates the upper soil layer will quickly become sub-surface flow, as the deeper soil layer is highly impermeable.

\section{Discussion and conclusion}

\section{Comparison of $\mathrm{K} f \mathrm{~s}$ formulas}

The resulting $K f s$ values using different solutions in Figure 2 illustrate how estimated $K f_{S}$ values differ, depending on the choice of solution. Each solution considers important physical properties influencing $K f s$. This shows the importance of understanding field conditions when measuring $K f s$, i.e. to consider the effects of physical influences such as smearing, soil capillarity and the ratio of $H / a$ to determine the correct boundary conditions along the submerged wetted surface of the auger hole. Using the Glover solution with a correction for gravity was based on careful investigation of the in-situ field conditions, experience of measuring the infiltration rates and observation of heavy rainfall field conditions.
Dominant flow pathways under tree and grass cover and NFM in the Scottish Borders

The very significant higher $K f s$ values under deciduous mature woodland are a striking contrast to the low $K f s$ values in the adjacent grassland areas (Figure 3). The dominant storm flow under deciduous woodland is more likely to be sub-surface flow, because the lower 15 to $25 \mathrm{~cm}$ soil layer is significantly more impermeable than the upper soil layer (Figure 4B) which could affect groundwater dynamics. The general consensus that tree cover has significantly higher $K f S$ values than grassland areas is proven not to be so distinct in terms of the conifer woodland (W3), where $K f_{s}$ is higher than the neighbouring grassland, but is not significantly different (Figure 3A). This could be because the higher gravel content for site 3 causes higher $K f S$ in grassland and/or the younger conifer forest has not had time to develop roots and alter the physical characteristics of the upper soil surface to allow it to become more permeable.

Clearly, in terms of NFM, improved grazed grassland hinders rainfall infiltration, whereas the mature deciduous forest provides the best conditions for storing storm rainfall. Planting coniferous plantations to decrease flood events is not obvious. Possibly, the plantation needs to mature and reproduce to develop a deeper forest soil structure to enhance rainfall infiltration. Interestingly, although W1 is approximately 320 years older than W2, the higher Ksat of W1 is not significantly different to W2. We can therefore conclude that a significantly older deciduous forest will not necessarily significantly increase $K f s$. This investigation illustrates that mature deciduous forest significantly increases rainfall infiltration and could facilitate the infiltration of heavy rainfall on upper catchment areas to prevent flood peaks entering groundwater and primary tributaries. However, more similar baseline research needs to be done to understand how woodlands should be managed to facilitate the development of more permeable soil.

It is unclear if $K f s$ values are comparable between different studies. For example, at Pontbren in Wales, Marshall et al. (2009) measured a greater order of magnitude difference between a 10-year old deciduous shelterbelt and adjacent improved grassland than was found in this investigation. The $K f_{s}$ median of the shelterbelt was calculated to be $8.34 \mathrm{~m} \mathrm{day}^{-1}$ (Marshall et al., 2009), which is significantly higher than the 500-year old deciduous forest site (W1) where the median was $3.86 \mathrm{~m} \mathrm{day}^{-1}$. These large measured differences between investigated sites are important to understand the dynamics of forest cover in relation to IDF characteristics.

\section{Acknowledgements}

This research was funded in part by the Scottish Government and the University of Western Australia and field work was supported from the British Geological Survey. We also thank Barony Hotel and the Walker family for permitting access to land and Winkston Farm for their hospitality.

\section{References}

Armit, I. and I. Ralston. 2003. The coming of iron, 1000 BC to AD 500. In: People and woods in Scotland, Smout, T.C (ed). Edinburgh Univeristy Press, Ltd., Edinburgh, UK.

Bloschl, G. and M. Sivapalan. 1995. Scale issues in hydrological modelling: a review. Hydrol. Processes., 9, 251-290.

Bonell, M. and L.A. Bruijnzeel. 2005. Forests, Water and People in the Humid Tropics: Past, Present and Future Hydrological Research for Integrated Land and Water 
Management. Cambridge University Press, Cambridge, UK.

Bonell, M., Purandara, B.K., Venkatesh, B., Krishnaswamy, J., Acharya, H.A.K., Singh, U.V., Jayakumar, R. and Chappell, N. 2010. The impact of forest use and reforestation on soil hydraulic conductivity in the Western Ghats of India: Implications for surface and sub-surface hydrology. J. Hydrol., 391, 47-62.

Bosch, D.D. 1997. Constant head permeameter formula dependence on alpha parameter. Trans. Amer. Soc. Agric. Eng., 40,1377-1379.

Carroll, Z.L., Bird, S.B., Emmett, B.A., Reynolds, B. and Sinclair, F.L. 2004. Can tree shelterbelts on agricultural land reduce flood risk? Soil Use Manage., 20, 357-359.

Elrick, D.E. and Reynolds, W.D. 1992. Methods for analyzing constant-head well permeameter data. Soil Sci. Soc. Amer. J., 56, 320-323.

Elrick, D.E., Reynolds. W.D and Tan, K.A. 1989. Hydraulic conductivity measurements in the unsaturated zone using improved well analyses. Groundwater Monit. Rev., 9, 184-193.

Elsenbeer, H. 2001. Hydrologic flowpaths in tropical rainforest soilscapes - A review. Hydrol. Processes., 15,1751-1759.

Faulkner, D. 1999. Flood estimation handbook. Procedures for flood frequency estimation: Volume 2: Rainfall frequency estimation. Institute of Hydrology, Wallingford, UK.

Scottish Government. 2009. The Flood Risk Management (Scotland) Act 2009, available at: http://www.legislation. gov.uk/asp/2009/6/pdfs/asp 20090006 en.pdf.

Mackney, E.C., Shewry, M.C. and Tudor, G.J. 1998. Land Cover Change: Scotland from the 1940s to the 1980s. The Stationary Office, London. 293.

Marshall, M.R., Francis, O.J., Frogbrook, Z.L., Jackson, B.M., McIntyre, N., Reynolds, B., Solloway, I., Wheater, H.S. and Chell, J.. 2009. The impact of upland land management on flooding: Results from an improved pasture hillslope. Hydrol. Processes., 23, 464-475.

Nisbet, T., Silgram, M., Shah, N., Morrow, K. and Broadmeadow, S. 2011. Woodland for water: woodland measures for meeting Water Framework Directive objectives. In: Forest Research Monograph. Vol. 4. Forest Research, Surry, UK. 156.
O’Connell, P.E., Beven, K.J., Carney, J.N., Clements, R.O., Ewen, J., Fowler, H.J., Harris, J., Hollis, J., Morris, J., O'Donnell, G.M., Packman, J.C., Parkin, A., Quinn, P.F., Rose, S.C., Shepherd, M. and S. Tellier, S. 2004. Review of impacts of rural land use and management on flood generation: Impact Study Report. R\&D Technical Report FD2114/TR. Joint Defra/EA Flood and Coastal Erosion Risk Management R\&D Programme.

Reynolds, W.D. and Elrick, D.E. 1987. A laboratory and numerical assesssment of the Guelph permeameter method. Soil Sci., 144, 282-299.

Reynolds, W.D., Elrick, D.E. and Topp, G.C. 1983. A reexamination of the constant head well permeameter method for measuring saturated hydraulic conductivity above the water table. Soil Sci., 136, 250-268.

Robinson, M., Cognard-Plancq, A.L., Cosandey, C., David, J., Durand, P., Führer, H.W., Hall, R., Hendriques, M.O., Marc, V., McCarthy, R., McDonnell, M., Martin, C., Nisbet, T., O'Dea, P., Rodgers, M. and Zollner, A. 2003. Studies of the impact of forests on peak flows and baseflows: A European perspective. Forest Ecol. Manage. 186, 85-97.

Scheffler, R., Neill, C., Krusche, A.V. and Elsenbeer, H. 2011. Soil hydraulic response to land-use change associated with the recent soybean expansion at the Amazon agricultural frontier. Agric, Ecosyst. Environ., 144, 2,81-289.

Soulsby, C., Piegat, K., Seibert, J. and Tetzlaff, D. 2011. Catchment-scale estimates of flow path partitioning and water storage based on transit time and runoff modelling. Hydrol. Processes., 23, 3960-3976.

Talsma, T. 1987. Re-evaluation of the well permeameter as a field method for measuring hydraulic conductivity. Aust. J. Soil Res. 25, 361-368.

Talsma, T. and Hallam, P.M. 1980. Hydraulic conductivity measurement of forest catchments. Aust. J. Soil Res., 18, 139-148.

Zangar, C.N. 1953. Theory and problems of water percolation. Engineering Monographs No. 8. United States Department of the Interior. Bureau of Reclamation, Denver, Colorado. 